\title{
PRODUCTION OF FIBROUS COMPOSITE MATERIAL WITH INCORPORATED ACTIVATED CARBON
}

\author{
${ }^{1}$ Pavel HOLEC, ${ }^{2}$ Ivan ULMAN, ${ }^{3}$ Radek JIRKOVEC, ${ }^{4}$ Jakub VANĚK \\ 1,2,3Technical University of Liberec, Liberec, Czech Republic, EU, pavel.holec@tul.cz, ivan.ulman@tul.cz, \\ radek.jirkovec@tul.cz \\ ${ }^{4}$ National Institute for Nuclear, Chemical and Biological Protection, Milin, Czech Republic, EU, \\ vanek@sujchbo.cz
}

https://doi.org/10.37904/nanocon.2020.3705

\begin{abstract}
The increasing emphasis on human health and safety presupposes, among other things, the development of new safety technologies and aids that should protect people in high-risk occupations, such as firefighters, soldiers, paramedics, chemical plant workers or researchers themselves. One of the most common type of protective equipment is protective clothing. In the second half of the 20th century, garments made of composite textiles with incorporated activated carbon particles have been used for the sorption of hazardous gaseous or liquid substances.

This work followed up on previous research and dealt with the design and production of a composite material with incorporated activated carbon, which was applied to the nonwoven material. The final product consisted of several layers: spun-bond, nonwoven needled fabric, activated carbon and nanofibers produced by polymer spinning technology using alternating current (AC spinning). The work also focused on the design of the order of individual layers, the method of application of activated carbon and the strengthening of the resulting composites. The finished material was finally subjected to tests of breathability, vapour permeability, loss of activated carbon particles and the passage of chemical warfare agents (simulants of sarin, soman or yperite). At the same time, the resulting composite was compared with the FOP-96 military protective clothing used today. The final product could serve as a protective layer for military purposes, firefighting, clothing for paramedics or the material for filtration.
\end{abstract}

Keywords: Chemical warfare agents, nanofibers, activated carbon, composite

\section{INTRODUCTION}

This article deals with design and production of composite material with the incorporation of sorbent - activated carbon, which was applied to the nonwoven material. The final product was composed of several layers spundbond, nonwoven textile with activated carbon [1] and nanofibers produced by AC spinning technology. The article deals with the design of layers, incorporation of activated carbon and the bonding of finished composites. The finished material was finally subjected to several tests, such as breathability, vapour permeability, decrease of activated carbon particles and penetration of chemical warfare agents [2]. The resulting material was compared with FOP-96 military clothing [3]. The final product should serve as a protective layer for military purposes.

\section{EXPERIMENT}

\subsection{Preparation of composite samples with activated carbon}

Samples of composite materials were prepared by layering of three types of nonwoven fabrics - spunbond (polyethylene-polypropylene, $16 \mathrm{~g} \cdot \mathrm{m}^{-2}$ ), needlepunched nonwovens (polyester, $80 \mathrm{~g} \cdot \mathrm{m}^{-2}$ ) and nanofiber layers (polyvinyl butyral, $50 \mathrm{~g} \cdot \mathrm{m}^{-2}$ ) produced by electrospinning using alternating voltage source (AC spinning). 
The polymer solution for nanofiber production was composed of polyvinyl butyral (Mowital B $60 \mathrm{H}$, $M_{n}=60,000 \mathrm{~g} \cdot \mathrm{mol}^{-1}$ purchased from Kuraray) at a weight concentration of $10 \%$, dissolved in denatured ethanol of $96 \%$ weight concentration (purchased from Technisolv). The polyvinyl butyral nanofibers showed a high degree of adhesion to other materials, which was later advantageously used to capture activated carbon particles in the structure of nanofiber layers. The polymer solution was spun using a screw pump [4] and alternating high voltage power source (VTS 36, purchased from KPB Intra) with an added residualcurrent device. The nanofibers were deposited on a spunbond base nonwoven fabric placed on a rotating collector. After reaching the required basis weight, the nanofiber layer was removed from the spunbond and further treated as other nonwoven layers.

It was necessary to find a compromise between bulk size of the composite, the possible application of the sorbent and maintaining its functionality after the

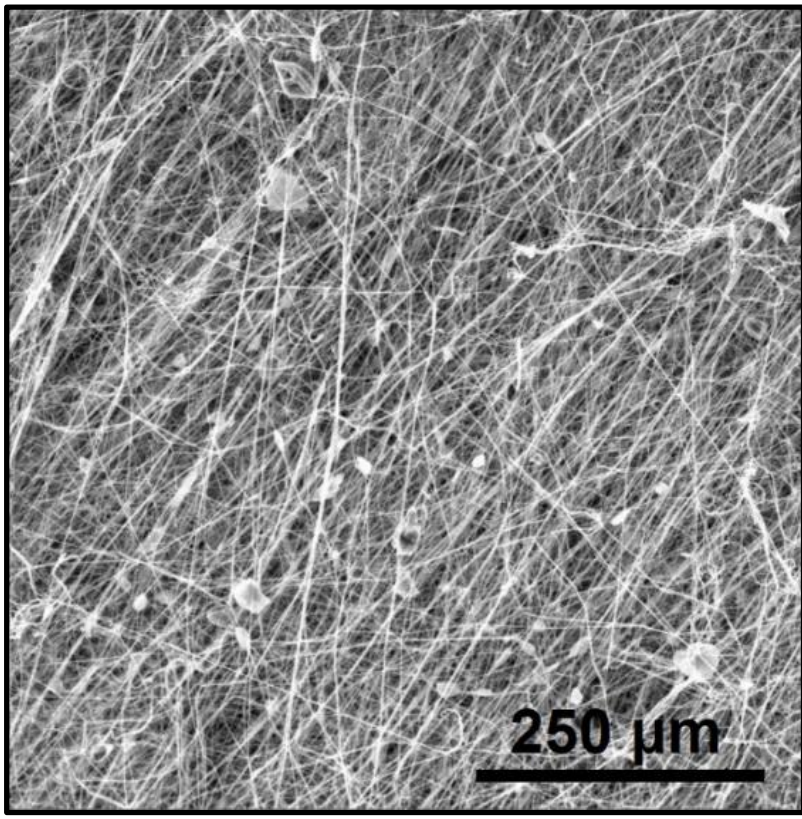

Figure 1 Nanofibers produced by AC spinning technology application of the activated carbon. After testing the various combinations of mentioned nonwovens, the following was subjectively selected as suitable: spunbond layer, needlepunch nonwoven, nanofiber layer, needlepunch layer with activated carbon and again nanofiber layer, needlepunch nonwoven and spunbond. The composite consisted of seven layers at all. Activated carbon was applied to the needled fabric in an amount of $90 \mathrm{~g} \cdot \mathrm{m}^{2}$ by the raking technique. Blank samples were made for further experiments. Its composition of layers was identical, but activated carbon was not added.

Subsequently, the samples were reinforced by lamination, hot-melt technology or a combination of sewing with ultrasonic bonding. Lamination was done by a laminator RPS-L 600 (Maschinenfabrik Herbert Meyer GmbH) without added pressure, at a temperature of $130{ }^{\circ} \mathrm{C}$ and a conveyor speed of $2.3 \mathrm{~m} \cdot \mathrm{min}^{-1}$. Poly- $\alpha$-olefin Helmitin 42048 (Forbo International SA) applied with a spray gun was used for hot-melt bonding. The Couptiss Ultra Sons HS $30(30 \mathrm{~W}, 40 \mathrm{kHz})$ with a relief sonotrode set at $15.5 \%$ power at a displacement speed of 2.5 $\mathrm{m} \cdot \mathrm{min}^{-1}$ and a pressure of 2 bar was used for ultrasonic bonding. Hagal UNIPOLY 120 thread (120 tex) was used for sewing. The holes caused by the penetration of the needle through the material were sealed using ultrasound, preventing the passing harmful substances.

\subsection{Testing methods}

Samples of manufactured composite materials reinforced by lamination, hot-melt technology or a combination of sewing and ultrasound were subjected to tests of activated carbon loss, breathability and vapour permeability. After comparing the results of individual types of composite reinforcement, two were selected, for further testing of the penetration of warfare agents or their simulants. These tests were performed by the National Institute for Nuclear, Chemical and Biological Protection.

Static activated carbon loss test - Samples were clamped in testing head of the device. They were then subjected to a vacuum at a given airflow rate for 1 minute. The vacuum value was set to achieve a constant airflow rate of $0.2 \mathrm{~mm} \cdot \mathrm{s}^{-1}$. The samples were weighed to three decimal places before and after testing and the absolute and relative loss of activated carbon from the sample was found. Initial amount of activated carbon was of $3 \mathrm{~g}$ per sample. 
Dynamic activated carbon loss test - The dynamic test was performed on a Vibramax 100 shaker (Heidolph Instruments $\mathrm{GmbH} \& \mathrm{CO} . \mathrm{KG}$ ). The samples were clamped to the vibrating plate of the device and the device subsequently performed a horizontal circular motion at a frequency of 1010 oscillations per minute for 10 minutes. Again, the absolute and relative loos of sorbent was found.

Breathability - Materials were tested for breathability using an SDL Atlas M021A (SDL Atlas). The measurement was performed according to the ČSN EN ISO 9237 standard. The pressure drop was $200 \mathrm{~Pa}$. The currently used military jacket FOP-96 was measured as well.

Vapour permeability - The measurement was performed on a Permetest (Sensora) device according to the ČSN EN ISO 11092 standard. Concerning the sample size, the measurement was performed only twice on each sample.

lodine resistance test - The resistance of the produced materials to the penetration of gaseous iodine was tested according to the internal methodology of National Institute for Nuclear, Chemical and Biological Protection [5]. The indicator solution was prepared from $1 \mathrm{~g}$ starch from potato (Sigma-Aldrich), which was dissolved in $50 \mathrm{ml}$ of distilled water. The resulting solution was then poured into $500 \mathrm{ml}$ of boiling distilled water and allowed to cool. The test apparatus consisted of two glass vessels, two silicone spacers and a distance ring. $3 \mathrm{ml}$ of the prepared starch solution were dispensed into the bottom vessel. A sample of the composite material was placed between a silicone spacer placed on the bottom vessel. A distance ring with an iodine tablet was placed on the upper silicone intermediate ring. The assembly was covered with a top cover vessel (see Figure 2). Colour changes on the indicator solution were monitored at $10 \mathrm{~min}$ intervals. The resistance time of the examined material to iodine vapour was determined as the time from the beginning of the experiment to the first signs of blueing of the indicator solution.

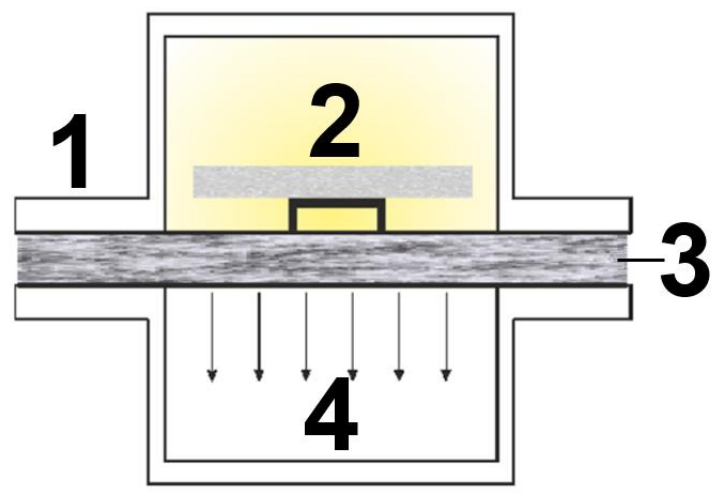

Figure 2 Schematic representation of a test chamber for testing of samples against the passage of dangerous substances - upper and lower glass cover vessel (1), a chamber with tablet or frit with warfare agent or its simulant on a distance ring (2), tested material (3) and chamber with an indicator solution with arrows indicating the direction of penetration of the used chemicals through the sample (4)

Soman resistance test - Indication solution was prepared from components A $(0.2 \mathrm{~g}$ of benzidine hydrochloride dissolved in $40 \mathrm{ml}$ of redistilled water and made up to $100 \mathrm{ml}$ with distilled ethyl alcohol), B ( $0.25 \mathrm{~g}$ of sodium perborate dissolved in $100 \mathrm{ml}$ of redistilled water) and $\mathrm{C}$ ( $10 \mathrm{~g}$ of sodium citrate dissolved in $100 \mathrm{ml}$ of redistilled water). Subsequently, all three components were mixed in a ratio of 1:2:2. Finally, a reference solution of 0.004 weight \% potassium dichromate in water was prepared. The apparatus for testing the resistance of the clamps to soman penetration was similar to the apparatus from the iodine resistence test. $2.5 \mathrm{ml}$ of indicator solution was poured into the lower vessel. $2.5 \mathrm{ml}$ of dichromate solution was poured into a comparison apparatus with a blank without activated carbon (i.e. only bonded layers of nonwovens). After tempering the whole apparatus and the used chemicals to $30^{\circ} \mathrm{C}, 5$ times $0.5 \mu \mathrm{l}$ of soman was applied to the tested sample in the testing and comparison apparatuses. The samples were sealed and tempered again. 
The resistance time of the samples to soman penetration was determined as the time from the start of the test to the colouring of the indicator solution to the same colour as the dichromate solution.

Material resistance test for DMMP, DCH and yperite - Measurements were performed under static conditions of $25{ }^{\circ} \mathrm{C}$ on a Kit Carousel 2000 [6]. Samples were tested by contamination with a frit dipped in dimethyl methyl phosphonate (DMMP), 1,6-dichlorohexane (DCH) or yperite. The wet frit was then placed on the distance ring above the measured sample. The testing scheme is shown in Figure 2.

\section{RESULTS AND DISCUSSION}

\subsection{Activated carbon loss test}

The results of the loss of activated carbon particles are shown in Table 1. Static and dynamic tests of particle loss showed that the formed composite maintained the sorbent in its structure. The decrease of carbon particles was smaller than 2 weight \%. The largest loss of particles occurred in the laminated sample (12\%), was done by the high value of the pressure drop required to achieve a given air flow rate.

Table 1 The results of activated carbon loss tests

\begin{tabular}{|c|c|c|c|c|c|c|}
\hline $\begin{array}{c}\text { Testing } \\
\text { method }\end{array}$ & Bonding method & $\begin{array}{c}\text { Vacuum } \\
{[\mathbf{k P a}]}\end{array}$ & $\begin{array}{c}\text { Initial weight } \\
\text { [g] }\end{array}$ & $\begin{array}{c}\text { Final weight } \\
{[\mathbf{g}]}\end{array}$ & $\begin{array}{c}\text { Absolute } \\
\text { loss } \\
{[\mathbf{g}]}\end{array}$ & $\begin{array}{c}\text { Percentage } \\
\text { loss } \\
{[\%]}\end{array}$ \\
\hline \multirow{3}{*}{ Static } & lamination & 17.0 & 15.083 & 14.720 & 0.363 & 12.1 \\
\cline { 2 - 7 } & hot-melt & 4.0 & 31.317 & 31.282 & 0.035 & 1.2 \\
\cline { 2 - 7 } & sewing+ultrasound & 3.3 & 17.616 & 17.587 & 0.029 & 1.0 \\
\hline \multirow{3}{*}{ Dynamic } & lamination & - & 15.149 & 15.096 & 0.053 & 1.8 \\
\cline { 2 - 7 } & hot-melt & - & 29.732 & 29.696 & 0.036 & 1.2 \\
\cline { 2 - 7 } & sewing+ultrasound & - & 18.813 & 18.782 & 0.031 & 1.0 \\
\hline
\end{tabular}

\subsection{Breathability}

The measured values of breathability for samples and blanks are given in Table 2. Along with the samples, an army jacket FOP-96 was measured. Product properties can be found on the manufacturer's website. The breathability of the material is greater than $100 \mathrm{I} \cdot \mathrm{m}^{-2} \cdot \mathrm{s}^{-1}$ [3]. The FOP-96 sample showed the highest rate of air passage, followed by hot-melt samples and laminated samples. Upon closer inspection, it was found that by laminating at $130^{\circ} \mathrm{C}$, the polyvinyl butyral nanofibers melted and formed an integral air barrier layer. The best results of the test from the point of view of breathability appeared to be laminated, then sewn with ultrasound and finally the sample bonded using the hot-melt technique. FOP-96 sample performed the worst.

Table 2 The results of breathability tests

\begin{tabular}{|c|c|c|}
\hline Sample & $\begin{array}{c}\text { Without activated carbon } \\
{\left[\mathbf{l} \cdot \mathbf{m}^{-2} \cdot \mathbf{s}^{-1}\right]}\end{array}$ & $\begin{array}{c}\text { With activated carbon } \\
{\left[\mathbf{l} \cdot \mathbf{m}^{-2} \cdot \mathbf{s}^{-1}\right]}\end{array}$ \\
\hline lamination & 5.6 & 4.9 \\
\hline hot-melt & 26.3 & 20.3 \\
\hline sewing+ultrasound & 20.0 & 16.8 \\
\hline FOP-96 & - & 200 \\
\hline
\end{tabular}




\subsection{Paropropustnost}

Table 3 shows the results of the vapour permeability test for samples of composites with and without activated carbon (blank). The laminated samples proved to have low permeability to water vapour and would therefore be unsuitable for use in the clothing industry. The hot-melt samples showed approximately the same properties as the FOP-96 military garment. The best results were achieved by samples bonded by combination of sewing and ultrasound, which even belong to degree of better comfort compartment than military clothing. Due to the results of vapour permeability measurements, the laminated sample was excluded from further penetration tests of warfare agents.

Table 3 Evaporative resistance and relative permeability to water vapour

\begin{tabular}{|c|c|c|c|c|c|c|c|}
\hline & lamination & hot-melt & $\begin{array}{c}\text { sewing } \\
\text { +ultrasound }\end{array}$ & $\begin{array}{c}\text { blank } \\
\text { lamination }\end{array}$ & $\begin{array}{c}\text { blank } \\
\text { hot-melt }\end{array}$ & $\begin{array}{c}\text { blank } \\
\text { sewing } \\
\text { +ultrasound }\end{array}$ & FOP-96 \\
\hline $\begin{array}{c}\text { Evaporative } \\
\text { resistance } \\
{\left[\mathrm{Pa} \cdot \mathrm{m}^{2} \cdot \mathrm{W}^{-1}\right]}\end{array}$ & 38 & 14,5 & 11,4 & 83,3 & 12 & 8,5 & 14,4 \\
\hline $\begin{array}{c}\text { Relative } \\
\text { permeability } \\
\text { to water } \\
\text { vapour [\%] }\end{array}$ & 13,3 & 28,5 & 32,9 & 6,5 & 32,3 & 40,2 & 28,6 \\
\hline
\end{tabular}

\subsection{The resistance of samples against penetration of warfare agents or their simulants}

The Table 4 summarizes the comparison of the results of tested samples bonded by the hot-melt method or a combination of sewing and ultrasound against the penetration of warfare agents and their simulants. The penetration of yperite was also tested on military clothing FOP-96. The samples bonded by sewing and ultrasound were able to resist to the tested chemical agents longer than hot-melt sample. Only exception was the iodine test. Both composites held yperite almost 5 times longer than the used army jacket FOR-96.

The evaluation of the resistance of samples was based on the standard ČSN EN 16523-1 and ČSN EN 165232. The evaluation criterion was the permeation rate $\mathrm{F}=1 \mu \mathrm{g} \cdot \mathrm{cm}^{2} \cdot \mathrm{min}^{-1}[7,8]$. In the case of chemical warfare agents, the lower permeation rate $\mathrm{F}=0.1 \mu \mathrm{g} \cdot \mathrm{cm}^{2} \cdot \mathrm{min}^{-1}[9]$ may also be used as a criterion.

Table 4 Results of the resistance of the samples against penetration of warfare agents or their simulants

\begin{tabular}{|c|c|c|c|c|c|}
\hline \multicolumn{7}{|c|}{ Retention time [min] } \\
\hline Sample & iodine & soman & DMMP & DCH & yperite \\
\hline hot-melt & 240 & 930 & 198 & 558 & 398 \\
\hline sewing+ultrasound & 195 & 1350 & 281 & 727 & 420 \\
\hline FOP-96 & - & - & - & - & 80 \\
\hline
\end{tabular}

\section{CONCLUSION}

The work describes the production of composite materials with activated carbon particles for capturing warfare agents. A composite material consisting of several layers of spun-bond nonwovens, needlepunch fabrics and nanofibers spun using alternating current electrospinning. Activated carbon was evenly introduced into the samples by raking. The layers were finally reinforced by lamination, hot melt technique or a combination of sewing and ultrasound.

Testing of breathability properties of samples shown its wind resistance (durability). Vapour permeability test demonstrated good properties of the product. Two of the composites were suitable for further clothing 
processing. Both static and dynamic measurements of particle loss shown, that the used nanofibers were able to keep the activated carbon particles in the material. The samples bonded by hot-melt technology and especially the samples bonded by combination of sewing and ultrasound shown better properties than in all directions the FOP-96.

The dependence of vapour permeability on the breathability of materials or a dependence of vapour permeability and breathability on pore sizes could be measured. The next step could be the development of a decontamination layer with metal oxides, which would help with the decomposition of hazardous substances. It would be appropriate to test a final material, which would consist of a covering ripstop layer with an oleophobic and hydrophobic coating, functional composite material described in this article, decontamination layers with metal oxide particles and lining.

\section{ACKNOWLEDGEMENTS}

The research was supported by the project reg. no. VI20172020059 provided by the Ministry of the Interior of the Czech Republic. Thanks also belongs to State Institute for Nuclear, Chemical and Biological protection in Brno for cooperation.

\section{REFERENCES}

[1] YANG, R. T. Adsorbents: fundamentals and applications. Hoboken, 2003. ISBN 04-712-9741-0

[2] HOENIG, S. L. Handbook of chemical warfare and terrorism. Westport, Conn.: Greenwood Press, 2002. ISBN 0313324077.

[3] BOIS - FILTRY, NBC ochranné oděvy - FOP-96. Bois - filtry [online]. Available from: http://www.bois-filtry.cz/nbcochranne-odevy.php

[4] TECHNICAL UNIVERSITY OF LIBEREC. A method of producing polymer nanofibres by electric or electrostatic spinning of a polymer solution or melt, a spinning electrode for this method, and a device for the production of polymer nanofibres fitted with at least one such spinning electrode. Inventors: BERAN, J., LUKAS, D., POKORNY, P. KALOUS, T., VALTERA, J., MAZDAMUNDI, S. CZ 307745. 27.2.2019.

[5] NATIONAL INSTITUTE FOR NUCLEAR, CHEMICAL AND BIOLOGICAL PROTECTION. Iodine testing method. Kamenná: SÚJCHBO. Internal method.

[6] SLABOTINSKÝ, J. a CEJPEK, J. Automatická aparatura pro vícemístné hodnocení kvality ochranných materiálů proti toxickým látkám Carousel 2000. In: Ochrana obyvatelstva - Dekontam 2013. SPBI Ostrava: 2013. ISBN 978-80-7385-122-4.

[7] ČSN EN 16523-1. Determination of resistance to chemical permeation of material - Part 1: Permeation of gaseous chemicals under permanent contact conditions. Czech Standards Institute, 2015.

[8] ČSN EN 16523-2. Determination of resistance to chemical permeation of material - Part 2: Permeation of liquid chemical under permanent contact conditions. Czech Standards Institute, 2015.

[9] ASTM F739. Standard Test Method for Permeation of Liquids and Gases through Protective Clothing Materials under Conditions of Continuous Contact. American National Standards Institute, 2012. 